\title{
Dissecting the Chromosome-Level Genome of The Asian Clam (Corbicula Fluminea)
}

\section{Tongqing Zhang}

Freshwater Fisheries Research Institute of Jiangsu Province

Jiawen Yin ( $\nabla$ jwyin_bio@163.com )

Freshwater Fisheries Research Institute of Jiangsu Province

Shengkai Tang

Freshwater Fisheries Research Institute of Jiangsu Province

\section{Daming Li}

Freshwater Fisheries Research Institute of Jiangsu Province

\section{Xiankun Gu}

Freshwater Fisheries Research Institute of Jiangsu Province

\section{Shengyu Zhang}

Hongze Lake Fisheries Administration Committee Office of Jiangsu Province

\section{Weiguo Suo}

Fisheries Management Commission of Gehu Lake

Xiaowei Liu

Freshwater Fisheries Research Institute of Jiangsu Province

\section{Yanshan Liu}

Freshwater Fisheries Research Institute of Jiangsu Province

\section{Qicheng Jiang}

Freshwater Fisheries Research Institute of Jiangsu Province

\section{Muzi Zhao}

Freshwater Fisheries Research Institute of Jiangsu Province

Yue Yin

Freshwater Fisheries Research Institute of Jiangsu Province

Jianlin Pan

Freshwater Fisheries Research Institute of Jiangsu Province

\section{Research Article}

Keywords: Asian Clam (Corbicula fluminea), Hi-C sequencing technologies, phylogenetic tree

Posted Date: April 29th, 2021 
DOl: https://doi.org/10.21203/rs.3.rs-451586/v1

License: (c) (1) This work is licensed under a Creative Commons Attribution 4.0 International License. Read Full License

Version of Record: A version of this preprint was published at Scientific Reports on July 22nd, 2021. See the published version at https://doi.org/10.1038/s41598-021-94545-2. 


\section{Abstract}

The Asian Clam (Corbicula fluminea) is a valuable commercial and medicinal bivalve, which is widely distributed in East and Southeast Asia. As a natural nutrient source, the clam is high in protein, amino acids, and microelements. The genome of $C$. fluminea has not yet been characterized; therefore, genomeassisted breeding and improvements cannot yet be implemented. In this work, we present a de novo chromosome-scale genome assembly of $C$. fluminea using PacBio and $\mathrm{Hi}-\mathrm{C}$ sequencing technologies. The assembled genome comprised 4,728 contigs, with a contig N50 of $521.06 \mathrm{~Kb}$, and 1,215 scaffolds with a scaffold N50 of $70.62 \mathrm{Mb}$. More than 1.51Gb (99.17\%) of genomic sequences were anchored to 18 chromosomes, of which $1.40 \mathrm{~Gb}(92.81 \%)$ of genomic sequences were ordered and oriented. The genome contains 38,841 coding genes, 32,591 (83.91\%) of which were annotated in at least one functional database. Compared with related species, $C$. fluminea had 851 expanded gene families and 191 contracted gene families. The phylogenetic tree showed that $C$. fluminea diverged from Ruditapes philippinarum, $\sim 228.89$ million years ago (Mya), and the genomes of $C$. fluminea and $R$. philippinarum shared 244 syntenic blocks. Additionally, we identified 2 MITF members and 99 NLRP members in $C$. fluminea genome. The high-quality and chromosomal Asian Clam genome will be a valuable resource for a range of development and breeding studies of $C$. fluminea in future research.

\section{Background}

The Asian Clam (Corbicula fluminea) belongs to the family Corbiculidae, genus Corbicula [1-2].The Asian Clam has a round base and triangular double shells. The surface of the shells is glossy, and the shell color varies with the living environment [3]. Shells are brown, yellow, green, or black and are characterized by circular growth lines [4]. There are three main teeth in the left shell, one in the front, one in the back and one in the side [5]. The Asian Clam experiences the planktonic larvae stage, grows rapidly and takes only 73-91 days for sexual maturation [6-7]. They are widely distributed in lakes and rivers in China, and play an important impact on the diversity of freshwater ecosystems [8]. The extant native distribution of $C$. fluminea is Asia, the Middle East, Africa and Australia [9]. In foreign countries, $C$. fluminea was first recorded as in the early 20th century [10]. They may have spread worldwide by carried as food resource /unintentionally attaching to the hull or though ballast waters, then occupying rivers and lakes and becoming alien invasive species in American and European ecosystems [11-13].

The meat of $C$. fluminea is delicious and nutritious, and thus the Asian Clam is considered as a delicacy. It is rich in protein, essential amino acids, taurine, active peptides, vitamins and microelements [14-15]. According to the Compendium of Materia Medica, the Asian Clam has medicinal applications of detumescence, dehumidification, sobering up, and benefits to the liver [16]. Modern research has found that the extracts of it can protect against liver damage and reduce blood lipids [17]. Compared with Japan and South Korea, the deep processing ability for the Asian Clam in China is underdeveloped, resulting in its economic and medicinal value not being fully exploited [18]. 
The Asian Clam as a benthic bivalves are critical in bioturbation, bioirrigation, and the breakdown of organic matter [19]. It displays strong environmental adaptability, reproductive capacity and diffusion ability [20]. The characteristic of the Asian Clam for the tolerance for diverse biotic and abiotic factors, such as antibiogram, heavy metal tolerance, hypoxia, surprised the people in the recent years [21]. The Asian clam has a robust and multifaceted immune system, which is strong enough to cope with all kinds of harsh living environment [22]. The underlying molecular mechanisms of mollusks for immune response and reproductive capacity still undergo a slow development, resulting in these processes is still very limited in $C$. fluminea. Deciphering the genome of $C$. fluminea is the most basic step in our research program. The acquisition of a high-quality genome may provide more detailed insights into the value of $C$. fluminea. During the past decade, whole-genome sequencing has been widely performed on a number of Mollusca due to the rapid development of third-generation sequencing [23-24].However, only $0.04 \%$ of the species described in Mollusca had available genome assemblies [25]. As the second most speciesrich phylum [26], the amount of Mollusca whole genomes is still lack and the assembly of their genomes still needs to move forward. In present study, a de novo genome sequencing of $C$. fluminea was performed, and this genome may provide the foundation for a range of development and breeding studies of $C$. fluminea in future research.

\section{Results}

\section{Genome sequencing assessment}

A total of $252.77 \mathrm{~Gb}$ of clean data were generated with the Illumina HiSeq PE150 platform, and the data covered the depth of 154.13X for the Asian Clam genome (Table S1). Two single-molecule real-time (SMRT) cells were responsible for producing data from PacBio Sequel platform, and approximately 15.03 million PacBio reads ( 293.72 Gb, 193.40 X) were generated (Table S1). The max subread for PacBio offline was $286.39 \mathrm{~kb}$; the N50 and mean length of subreads were $31.18 \mathrm{~kb}$ and $19.54 \mathrm{~kb}$, respectively. Two libraries for the high-throughput chromosome conformation capture technology (Hi-C) were employed, yielding a total of 780.87 million clean reads ( 233.26Gb, 142.23X) (Table S1). Additionally, approximately $8 \mathrm{~Gb}$ clean data of transcriptomic data was obtained for genome annotation.

\section{Genome estimation and assembly}

The k-mer analysis yielded more than 187.45 billion k-mers, which was used to calculate the genome size. The main peak of k-mer was the depth of 115 , from which the genome size was estimated to be $1.64 \mathrm{~Gb}$ (Fig. S1). The k-mer depths of 58 and 230 estimated a heterozygosity rate of $2.41 \%$ and a repeat ratio of $64.55 \%$ for the Asian Clam genome, respectively.

Canu was responsible for correcting the 15.03 million subreads from PacBio platform. Canu and Wtdbg assembled the subreads individually and then merged the results. After contig assembly and errorcorrected procedures, the initial 4,347contigs were obtained. The draft genome assembly of Asian Clam resulted in a genome size of $1.52 \mathrm{~Gb}$, with a contig N50 size of $603.64 \mathrm{~Kb}$. 


\section{Chromosome construction by Hi-C}

A total of 571.60 million read pairs $(73.20 \%)$ of total $\mathrm{Hi}-\mathrm{C}$ data were mapped to the draft genome assembly, and 116.65 million valid interaction pairs (14.94\%) played a role in the assembly (Table S2). The contigs of the draft genome (4,347contigs) were broken and reassembled using the valid interaction pairs, yielding 4,728 corrected contigs. The final assembly presented a high-quality genome of the $C$. fluminea that reached $1.52 \mathrm{~Gb}$ in length, and it was characterized by a contig N50 of $521.06 \mathrm{~Kb}$ and a scaffold $\mathrm{N} 50$ of $70.62 \mathrm{Mb}$. The final genome comprised 1,215 scaffolds, and the mix contig and scaffold were $3.17 \mathrm{Mb}$ and $144.27 \mathrm{Mb}$, respectively.

The high-throughput chromosome conformation capture technology $(\mathrm{Hi}-\mathrm{C})$ realized the real sense of chromosome construction. A total of $1.51 \mathrm{~Gb}$ of genomic sequences accounting for $99.17 \%$ of total sequences, were assigned to 18 haploid chromosomes. (Fig. 1). Among the 4,728 corrected contigs, 4,621 contigs $(97.74 \%)$ were anchored onto 18 haploid chromosomes. Additionally, $1.40 \mathrm{~Gb}$ (92.81\%) of genomic sequences were anchored with a defined order and orientation (Table S3).

\section{Evaluation and repetitive genome elements}

The BUSCO data showed the Asian Clam genome covered $90.90 \%$ of the complete core genes, and the CEGMA data showed it contained $92.36 \%$ of the complete core genes (Table S4). The $97.45 \%$ of Illumina reads successfully mapped back to the assembly, indicating the high degree of completeness of the Asian Clam genome. More than $1.06 \mathrm{~Gb}$ of genomic sequences were identified andmarked as repeats, representing $69.66 \%$ of the total genomic sequences. Approximately $608.85 \mathrm{Mb}(57.54 \%)$ of the Asian Clam genome consisted of LARDs, which was the predominant repeat. TIRs, PLEs, and LINEs comprised $10.46 \%, 12.38 \%$, and $7.07 \%$ of the Asian Clam genome, respectively (Table S5).

\section{Gene prediction and gene annotation}

A consensus of the results of all three methods for protein-coding genes prediction was reached, and the final number of non-redundant protein-coding genes was 38,841, with a total length of $0.54 \mathrm{~Gb}$ (Table S6). More than 32,591 protein-coding genes (83.91\%) were annotated in at least one functional database (Table S7). All genes for each database are annotated in Table S8. Additionally, the Asian Clam gene sets comprised 260,971 exons, and the average gene length was $13.97 \mathrm{~kb}$. The Asian Clam genome contained 3,048 pseudogenes, 45 microRNAs, 420 rRNAs, and 3,707 tRNAs (Table S9). Finally, the whole genome of the Asian Clam had been recognized clearly (Fig. 2a).

\section{Comparative result of $\mathrm{C}$. fluminea and Ruditapes philippinarum Genomes}

The genomic statistics of $C$. fluminea compared to that of $R$. philippinarum, showing the improvement in many aspects (Table 1$)$. The assembly work for $C$. fluminea genome, with a high repeats $(69.66 \%)$ and a heterozygosity rate $(2.41 \%$ ), was much more difficult than that of $R$. philippinarum (repeats of $38.29 \%$; 
heterozygosity rate of $1.03 \%$ ). The scaffold N50 for $C$. fluminea was $70.62 \mathrm{Mb}$, whereas that for $R$. philippinarum was $56.47 \mathrm{Mb}$. The contig N50 of $521.06 \mathrm{~Kb}$ for $C$. fluminea was much higher than that of $28.11 \mathrm{~kb}$ for $R$. philippinarum. These results suggest that the $C$. fluminea genome, which is assembled on the basis of PacBio reads, Illumina reads, and $\mathrm{Hi}-\mathrm{C}$ data, is of high quality. Compared with the estimated genome size of $R$. philippinarum ( $1.32 \mathrm{~Gb}$ ), that of $C$. fluminea was larger (1.64Gb). The genome assembly work for $R$. philippinarum eventually produced a genome size of $1.12 \mathrm{~Gb}$, which covered $84.85 \%$ of the estimated genome. The $C$. fluminea genome assembled a total of $1.52 \mathrm{~Gb}$ of genomic sequences, which covered $92.68 \%$ of the estimated genome. The other comparisons, including gene mean length, BUSCO evaluation, and the number of coding genes, etc., showed the genomic characteristics for these two species (Table 1). There were 19 and 18 chromosomes in R. philippinarum and $C$. fluminea genomes, respectively. The longest chromosome for $C$. fluminea was the chromosome 01 , with a length of $144.27 \mathrm{Mb}$, whereas the longest chromosome 19 for $R$. philippinarum was only 62.15 $\mathrm{Mb}$ (Table S10). Incredibly, the longest chromosome 01 for $C$. fluminea also happened to be the maximum scaffold we assembled, suggesting the high efficiency of our assembly work. The syntenic analysis generated 244 syntenic blocks between two genomes (Fig. 2b, Table S10). Among that, the most 35 blocks on chromosome 05 of $C$. fluminea were discovered in the genome of $R$. philippinarum, of which 30 blocks occurred on chromosome 19 of $R$. philippinarum. The other relatively high collinearities between $C$. fluminea and $R$. philippinarum genomes were that 26 blocks on chromosome 02 of $C$. fluminea matched the chromosome 17 of $R$. philippinarum; 18 blocks on chromosome 09 of $C$. fluminea matched the chromosome 02 of $R$. philippinarum; 17 blocks on chromosome 06 of $C$. fluminea matched the chromosome 01 of $R$. philippinarum, etc. The chromosome 04 and 08 of $C$. fluminea contained the least blocks, on which was 3 blocks. The blocks on chromosome $06,10,13,16$ and 18 of $C$. fluminea individually matched the unique chromosomes in $R$. philippinarum genome. 
Table 1

Comparative Analysis between the Genome of Corbicula fluminea and the Genome of Ruditapes philippinarum

\begin{tabular}{|c|c|c|}
\hline Characteristics & Corbicula fluminea & Ruditapes philippinarum \\
\hline $\begin{array}{l}\text { Estimate of } \\
\text { genome size }\end{array}$ & $1.64 \mathrm{~Gb}$ & $1.32 \mathrm{~Gb}$ \\
\hline $\begin{array}{l}\text { Final assembly } \\
\text { genome size }\end{array}$ & $1.52 \mathrm{~Gb}$ & $1.12 \mathrm{~Gb}$ \\
\hline Contig N50 length & $521.06 \mathrm{~Kb}$ & $28.11 \mathrm{~Kb}$ \\
\hline $\begin{array}{l}\text { Maximum contig } \\
\text { length }\end{array}$ & $3.17 \mathrm{Mb}$ & $249.66 \mathrm{~Kb}$ \\
\hline $\begin{array}{l}\text { Scaffold N50 } \\
\text { length }\end{array}$ & $70.62 \mathrm{Mb}$ & $5.65 \mathrm{Mb}$ \\
\hline $\begin{array}{l}\text { Maximum } \\
\text { scaffold length }\end{array}$ & $144.27 \mathrm{Mb}$ & $20.46 \mathrm{Mb}$ \\
\hline $\begin{array}{l}\text { Average } \\
\text { chromosome } \\
\text { length }\end{array}$ & $77.68 \mathrm{Mb}$ & $48.66 \mathrm{Mb}$ \\
\hline $\begin{array}{l}\text { Maximum } \\
\text { chromosome } \\
\text { length }\end{array}$ & $144.27 \mathrm{Mb}$ & $62.15 \mathrm{Mb}$ \\
\hline $\begin{array}{l}\text { Minimum } \\
\text { chromosome } \\
\text { length }\end{array}$ & $57.93 \mathrm{Mb}$ & $25.99 \mathrm{Mb}$ \\
\hline $\begin{array}{l}\text { Heterozygosity } \\
\text { rate }\end{array}$ & $2.41 \%$ & $1.03 \%$ \\
\hline $\begin{array}{l}\text { Repeat } \\
\text { percentage }\end{array}$ & $69.66 \%$ & $38.29 \%$ \\
\hline $\begin{array}{l}\text { Total protein- } \\
\text { coding genes }\end{array}$ & 38,841 & 27,652 \\
\hline $\begin{array}{l}\text { Average gene } \\
\text { length }\end{array}$ & $13.97 \mathrm{~Kb}$ & $12.87 \mathrm{~Kb}$ \\
\hline $\begin{array}{l}\text { BUSCO } \\
\text { assessment }\end{array}$ & $\begin{array}{l}\text { C: } 90.9 \% \\
\text { [S:73.7\%,D:17.2\%],F:2.7\%,M:6.4\%,n:978 }\end{array}$ & $\begin{array}{l}\text { C: } 91.0 \% \\
{[S: 89.3 \%, D: 1.7 \%], F: 3.9 \%, M: 5.1 \%, n: 978}\end{array}$ \\
\hline
\end{tabular}

\section{Analysis of protein families}

Gene family analysis identified a total of 71,331 gene families among five kinds of bivalves (Table S11), and we discovered 23,063 gene families clustered by 38,841 protein-coding genes in the Asian Clam genome. Compared with the genome of $R$. philippinarum, Crassostrea gigas, Crassostrea virginica, and $B$. platifrons, the $C$. fluminea genome had 16,170 specific gene families (Fig. 3a). Additionally, Single-copy 
orthologs, multiple copy orthologs, other orthologs, and unique genes were identified in the all-to-all BLASTP analysis of entries for the reference genomes. The five bivalve species shared 146 single-copy orthologs, and the Asian Clam genome contained 25,878 unique genes (Fig. 3b, Table S12).

\section{Phylogenetic and gene family expansion analysis}

The phylogenetic relationship between $C$. fluminea and other representative species was estimated based on single-copy orthologs. Three time points for the most recent common ancestor (MRCA) were estimated by TimeTree. The differentiation time of Crassostrea gigas and Crassostrea virginica was 72.9 (63.2-82.7) million years ago (Mya) [77]; that of B. platifrons and Mytilus coruscus was 387 (308-481) Mya [78]; that of $C$. fluminea and $R$. philippinarum was 244 (114-280) Mya [79]. We utilized these time of MRCA to calibrate the phylogenetic tree, resulting in the phylogenetic tree constructed by eight bivalves and four other molluscas species (Fig. 3c). As shown, all bivalves were clustered together, especially those belong to the same family/order. The phylogenetic tree showed that $C$. fluminea and its closest relative, $R$. philippinarum, diverged at an early stage of $\sim 228.89$ million years ago. The ancestors of $C$. fluminea and $R$. philippinarum, diverged from the common ancestors of other six marine bivalves (family Mytilidae represented by $B$. platifrons and Mytilus coruscus; family Ostreidae represented by Crassostrea gigas and Crassostrea virginica; family Pteriidae represented by Pinctada imbricata; family Pectinidae represented by Mizuhopecten yessoensis), 492.00 million years ago. This evidence suggests that as a freshwater bivalve, $C$. fluminea had been diverged from other bivalves million years ago.

Combining the phylogenetic relationships, gene family evolution was calculated by comparing the differences between ancestors and $C$. fluminea. This analysis resulted in 851 gene families being significantly expanded $(P<0.05)$ and 191 gene families being significantly contracted $(P<0.05)$ in the Asian Clam genome (Fig. 3c, Table S13). The 851 expanded gene families were clustered by 9,967 functional genes (Table S14). The functional enrichment analysis on GO and KEGG of those expanded genes identified 325 significantly enriched (q-value < 0.01) GO terms (Table S15) and 19 significantly enriched (q-value < 0.01) KEGG pathways (Fig. S2, Table S16). Among the significantly enriched KEGG pathways, we found taurine and hypotaurine metabolisms were significantly enriched.

\section{MITF gene family analysis}

The genic tree comprising all MITF family genes was successfully constructed using MUSCLE (Fig. 4a). Most species possessed one or two MITF members, while Lottia gigantea lost MITF members.

Crassostrea virginica and $L$. anatine possessed five and seven MITF members, respectively (Table S17). This result coincides with the result of the above gene family evolution analysis, which showed the MITF gene family expanded in Crassostrea virginica and Lingula anatina, and contracted in Lottia gigantean (Table S18). The genic tree also showed that MITF members originated from the same species were clustered at the nearest genetic distance. MITF members from the same families (family Mytilidae represented by B. platifrons and Mytilus coruscus, family Ostreidae represented by Crassostrea gigas and Crassostrea virginica), were clustered more together. The clustering relationships of MITF gene family 
were similar to those shown by the phylogenetic tree of single-copy orthologs. This finding indirectly corroborates the reliability of the phylogenetic relationship analysis.

In this study, we detected two members from the Asian Clam genome, namely EVM0008002 and EVM0031201, which were identified as MITF genes. Both genes contained an N-terminal domain TFEB_C_3 and a highly conserved functional domain HLH. The EVM0008002 was located at $47.05 \mathrm{Mb}-$ $47.08 \mathrm{Mb}$ on chromosome 10 , with a length of $28,761 \mathrm{bp}$, and encoded 533 amino acids. The position of EVM0031201 was close to that of EVM0008002, and it was also located on chromosome 10 . The EVM0031201 was located at $46.99 \mathrm{Mb}-47.02 \mathrm{Mb}$, with a length of $29,767 \mathrm{bp}$, and it encoded 533 amino acids, too. Both EVM0008002 and EVM0031201 contained 8 exons that comprising 533 amino acids, and 7 introns. The domain TFEB_C_3 of them started with 130 amino acids and ended with 268 amino acids, and was accompanied by 3 exons. The domain HLH of them started with 352 amino acids and ended with 405 amino acids, and was accompanied by 3 exons, too (Fig. 4b). Among 533 amino acids, the types and sequences of 530 amino acids for these two genes were consistent, only three amino acids showed the differences. The three differences of amino acids were located at position of 87,89 , and 90 , respectively. Specifically, the amino acids of EVM0008002 at position of 87,89 , and 90 , were Leucine (L), Histidine $(\mathrm{H})$, and Alanine $(\mathrm{A})$, respectively. The amino acids of EVM0031201 at position of 87, 89, and 90, were Histidine $(H)$, Asparagine $(N)$, and Threonine (T), respectively (Fig. 4b).

\section{NLRP gene family analysis}

NLRP (Nucleotide-binding oligomerization domain, Leucine rich Repeat and Pyrin domain containing Proteins) is well known for its roles in apoptosis and inflammation. Among all the species involved in the evolutionary analysis, the number of NLRP members in $C$. fluminea (99) was more than that of most species, except $P$. imbricata (150) and Capitella teleta (105) (Fig. 5a). Specifically, the number of NLRP members in C. fluminea was more than that shown in B. platifrons (12), Mytilus coruscus (16), Mizuhopecten yessoensis (22), Crassostrea gigas (28), Crassostrea virginica (47). Additionally, we analyzed the domain NACHT of $C$. fluminea (99) in the table of the expanded gene families in $C$. fluminea (Table S14), which was significantly expanding compared to its ancestors (10). Among the 99 NLRP members in $C$. fluminea genome, 45 members possessed domain DUF4559, 12 members possessed domain DUF4062, and 5 members possessed the domain WD40, etc. (Fig. 5b, Table S19). Meanwhile, we found that all five members (EVM0034661, EVM0036165, EVM0036449, EVM0010937 and EVM0021611) contained 3 domains, and two members (EVM0032343 and EVM0035132) contained 4 domains. The NLRP members of $C$. fluminea grouped into five subfamilies (subfamily a-e)

(Fig. 5c).Subfamily aowned 12 members clustered by the same or similar protein domains, as the same as subfamily $b$ to e possessed $36,3,18$, and 25 members, respectively (Table S20). Five of 99 members did not cluster into any subfamily.

\section{Methods}

\section{Sample collection and DNA isolation}


Fresh Asian Clam (C. fluminea) samples were collected from Hongze Lake (118.18 E, 33.22 N), Jiangsu, China. Healthy and disease-free individuals of $C$. fluminea were selected as sequencing individuals. After the physical removal of shells and gut content, the whole soft bodies were immediately transferred into liquid nitrogen. High-quality genomic DNA was extracted from the body of Asian Clam using a DNeasyR Blood\& Tissue Kit (Qiagen, Hilden, Germany). The DNA quality was measured with Qubit 3.0 (Invitrogen, Carlsbad, CA, USA) and was checked using $1 \%$ agarose gel electrophoresis.

\section{Library preparation and sequencing}

Whole-genome shotgun sequencing

The libraries of short insert size (350 bp) for Illumina were constructed according to the manufacturer's standard PCR-free protocol (Illumina) and sequenced on an Illumina HiSeq X Ten platform (Illumina, Inc., San Diego, CA, USA) using the paired-end 150 (PE150) strategy. Six Illumina libraries were used to produce data for survey analysis and PacBio error correction.

Pacific Biosciences Technologies

Approximately $30 \mu \mathrm{g}$ of genomic DNA was used to construct PacBio libraries by shearing into $\sim 20 \mathrm{~kb}$ targeted size fragments with Blue Pippin (Sage Science, Beverly, MA, USA). Then, the qualified libraries were prepared for single-molecule real-time (SMRT) genome sequencing using S/P2-C2 sequencing chemistry on the PacBio Sequel II platform (PacBio, Pacific Biosciences, USA). Two PacBio libraries generated data for genome assembly.

Hi-C technologies

The Hi-C libraries were cross-linked in situ using formaldehyde with a final concentration of $2 \%$ and homogenized with tissue lysis by the restriction enzyme Hindlll. The libraries for Hi-C with insert sizes of 300-700 bp were sequenced on an Illumina HiSeq X Ten platform (Illumina, SanDiego, CA, USA). Two HiC libraries generated data for chromosomal building.

Transcriptome sequencing

The RNA was extracted using TRIzol (Thermo Fisher, USA), and the libraries were generated using a NEBNext ${ }^{\circledR}$ Ultra ${ }^{\mathrm{TM}}$ RNA Library Prep Kit for Illumina ${ }^{\circledR}$ (NEB, USA) following the instruction manual. The data was used to alignment to the assembled genome for prediction of coding genes.

\section{Genome estimation}

Illumina reads were aligned to the Nucleotide Sequence Database (NT) using BLAST (version 2.2.31) [27] with the parameter of E-value $=1 \mathrm{e}^{-05}$ for pollution verification. Then, Illumina data were filtered and corrected by Fastp (version 0.19.3) [28], followed by k-mer analysis to estimate the genomic features. In this study, we plotted the 21-mer depth distribution $(k=21)$ to estimate the genome size, heterozygosity, and repeats using Jellyfish (version 2) [29]. Genome size estimation was implemented by the formula $G=$ 
N21-mer (total number of k-mers) /D 21-mer (k-mer depth of the main peak). The repetitive content was accumulated from where the depth of k-mer was more than two times of the main peak, and the heterozygosity were estimated at where the depth was half of the main peak.

\section{Denovo assembly}

Using the long single molecular reads from PacBio, the pipelines of workflow were as follows in the genome assemblies. Firstly, the clean data from PacBio were subjected to error correction using Canu (version 1.5) [30] with the parameter of error correct coverage $=60$. Subsequently, the outputs were piped into the workflow of SMART denovo (version 1.0) [31], and the genomic contigs were automatically generated with the parameters of $J=5000, A=1000$, and $r=0.95$. Finally, the preliminary assembly was polished three times by Racon (version 1.32) [32], resulting in the first correction being successfully realized. Illumina reads specifically for genome estimation were prepared for the second correction, and this round of correction could solve the high error rate of the third generation sequencing. The third round of correction was implemented by Pilon (version 1.22) [33], and the error correction was run for three times.

\section{Hi-C scaffolding}

The contigs generated by the preliminary genome assembly required filling of gaps and anchoring on the putative chromosomes. The initial contigs were piped into the $\mathrm{Hi}-\mathrm{C}$ assembly workflow, and the signals of chromatin interactions were captured to construct chromosomes. In brief, the putative Hi-C junctions were aligned by the unique mapped read pairs using BWA-MEM (version 0.7.10-r789) [34]. The paired reads uniquely mapped to the assembly were called the valid interaction pairs, and they were used for the Hi-C scaffolding. Other invalid reads included reads of self-ligation and non-ligation; dangling ends were filtered out using HiC-Pro (version 2.10.0) [35]. The Hi-C reassembly broke the contigs into $50 \mathrm{~kb}$ fragments, and the regions that were mismatched to the initial assembly or could not be restored were listed as candidate error areas. The genome was subjected to a final round of error correction, and the gaps were filled during this round. The reassembled and corrected contigs were divided into ordered, oriented, and anchored groups by LACHESIS [36] with the parameters CLUSTER_MIN_RE_SITES = 33; CLUSTER_MAX_LINK_DENSITY = 2; CLUSTER_NONINFORMATIVE_RATIO = 2;

ORDER_MIN_N_RES_IN_TRUN $=29$, and ORDER_MIN_N_RES_IN_SHREDS $=29$, automatically resulting in putative chromosomes. The gaps generated during the Hi-C assembly were refilled using LR GapCloser (version 1.1) [37].

\section{Genome quality evaluation}

The genome of $C$. fluminea was aligned to the actinopterygii database (odb9) comprising 978 conservative core genes by BUSCO (version 3.0) [38]. The CEGMA Database comprising 458 conserved core genes of eukaryotes was searched in the same way using CEGMA (version 2.5) [39]. The lllumina short-read alignments mapped to the assembled genome of the Asian Clam using BWA-MEM (version 0.7.10-r789) [34].

\section{Repeats analysis}


There are two main types of repeats, retrotransposons (Class I in our analysis) and transposons (Class II in our analysis). We constructed a specific repeats database for repeat prediction using LTR-FINDER (version 1.05) [40] and RepeatScout (version 1.0.5) [41], followed by the identification and classification for repeats by PASTEClassifer (version 1.0) [42]. The species-specific repeats library for the Asian Clam genome was successfully generated by aggregating our prediction and Repbase (19.06) [43]. LTR characteristics for the clam were processed by RepeatMasker (version 4.0.6) [44].

\section{Genome annotation}

Gene annotation

We utilized de novo-, homology-, and transcriptome-based methods to predict protein-coding genes. Five tools employed were Genscan (verson3.1) [45], Augustus (version 3.1) [46], GlimmerHMM (version 3.0.4) [47], GenelD (version 1.4) [48], and SNAP (version 2006-07-28) [49]; these were used for prediction de novo. Protein sequences from four representative species (Danio rerio, Crassostrea gigas, Crassostrea virginica, and Mizuhopecten yessoensis) were aligned to the Asian Clam protein sequences to perform homology-based prediction by GeMoMa (version 1.3.1) [50]. Transcriptome data were mapped to the genomic sequences; Hisat (version 2.0.4) [51] and Stringtie (version 1.2.3) [52] were used to assemble and dissect functional genes. TransDecoder (version 2.0) (http://transdecoder.github.io) and GeneMarkS$\mathrm{T}$ (version 5.1) [53] were used for transcriptome-based prediction. Finally, the above methods were integrated into non-redundant protein-coding gene sets by EVM (version 1.1.1) [54] and PASA (version 2.0.2) [55].

Non coding gene annotation

The other genome features, including pseudogenes and non-coding RNAs, were identified by referring to the miRbase database (version 21.0) [56]and Rfam (version 13.0) [57].In the process of searching for putative pseudogenes, candidates were assessed based on the premature stop codons or frame shift mutations in the gene structure using GenBlastA (version 1.0.4) [58]. The identification of transfer RNA (tRNA) was performed by tRNAscan-SE (version 1.3.1) [59]. MicroRNA and ribosomal RNA (rRNA) were identified by Infernal (version 1.1) [60].

Gene function annotation

The protein-coding genes were subject to functional annotation by aligning to the EuKaryotic Orthologous Groups (KOG) [61], Kyoto Encyclopedia of Genes and Genomes (KEGG) [62], TrEMBL[63], Swiss-Prot[63], and Non-redundant (Nr) databases[64] using BLAST (version 2.2.31) [27] with a maximal E-value of 1e 05. Kyoto Encyclopedia of Genes and Genomes (KEGG) pathway annotations and Gene ontology (GO) [65] terms were assigned to identify gene functions using Blast2GO (version 4.1) [66].

\section{Comparative Analysis of C. fluminea and R. philippinarum Genomes}


The genome data of R. philippinarum (https://doi.org/10.1016/j.isci.2019.08.049, 2019) that is also belonging to the order Veneroida was used to conduct the comparative analysis with the $C$. fluminea genome. The process of the comparison included genome size, assembly index, evaluation and collinearity, which was helpful to better understand the genome of $C$. fluminea. For collinearity analysis, we compared the $C$. fluminea genome with the genome of $R$. philippinarum using MUMmer (http://mummer.sourceforge.net), with the parameter $I=10,000$. The genomes of $C$. fluminea and $R$. philippinarum were subjected to a synteny analysis to show the connections and syntenic blocks using $\operatorname{BLASTP}(E<1 e-05)$ [27]. Each syntenic block comprised at least five sequential genes, which were all distributed in two genomes.

\section{Gene family identification}

Protein data from $C$. fluminea and other representative species (all Bivalve species and some mollusks with assembly and annotation that could be found in NCBI or other databases), including Capitella teleta, Lingula anatina, Octopus vulgaris, Lottia gigantea, R. philippinarum, Crassostrea gigas, Crassostrea virginica, P. imbricata, Mizuhopecten yessoensis, Mytilus coruscus, and Bathymodiolus platifrons, were retrieved in the corresponding databases and aligned using BLAST (version 2.2.31) [27] with a maximum e-value of $1 e-5$. Proteins with sequence lengths $>100$ amino acids were searched against the Pfam (https://pfam.xfam.org) database by Pfam scan [67]. Protein sequences were clustered using CD-HIT [68], with a length difference cutoff of 0.7 , and finally concatenated to a single fasta file. The ortholog groups for gene families were generally clustered using OrthoMCL (version 2.0.9) [69]. Four selected bivalves (R. philippinarum, Crassostrea gigas, Crassostrea virginica, and B. platifrons) and C. fluminea were grouped together to conduct the analysis for gene family characteristics.

\section{Phylogenetic tree reconstruction and divergence time estimation}

The single-copy orthologs from all involved species were statistically analyzed using the longest transcripts for each gene. The single-copy orthologous genes shared by the above 12 species (including C. fluminea) were aligned using MUSCLE (version 3.8.31) [70]. The super-alignment of nucleotide sequences provided a reference tree topology using PhyML (version 3.3) [71]. The divergence times among species were roughly estimated by the MCMC Tree program of the PAML package (version 4.7a) [72] with the approximate likelihood calculation method. We utilized molecular clock data from the TimeTree (http://www.timetree.org/) [73] database as the calibration times.

\section{Gene family evolutionary analysis}

According to divergence times and phylogenetic relationships, CAFÉ (version 4.2) [74] was used to analyze gene family evolution. The gene family expansion and contraction were analyzed by comparing the differences between the ancestor and involved species. The expanded family genes for $C$. fluminea were extracted and aligned to the functional enrichment on GO and KEGG to detect their functions.

\section{Prediction of specific protein domains}


Pfam database provided protein domains, and the specific proteins with sequence lengths $>100$ amino acids, were searched against it for specific gene families analysis. The MITF gene family consisted of three domains, namely TFEB, TFEC, and TFE3 [75]. In this study, we utilized protein-coding sequences from the representative species to analyze the members of MITF gene family, especially the structure and amino acid composition of members in the $C$. fluminea genome. The core domain of NALP family was NACHT [76], which was used to analyze the structure and distribution of NALP family members in $C$. fluminea genome.

\section{Discussion}

In this study, we assembled a chromosome-level Asian Clam genome using a combination of PacBio and $\mathrm{Hi}-\mathrm{C}$ technology. Generally, a complex genome is defined as a heterozygosity ratio greater than $0.8 \%$ and a repeat ratio greater than $60 \%$. The high repeats $(69.66 \%)$ and heterozygosity rate $(2.41 \%)$ of $C$. fluminea genome bring great difficulties to assembly, we still assembled and obtained a high-quality and chromosomal genome. The $1.52 \mathrm{~Gb}$ of genome data distributed across 18 chromosomes, with a contig $\mathrm{N} 50$ of $521.06 \mathrm{~Kb}$ and a scaffold $\mathrm{N} 50$ of $70.62 \mathrm{Mb}$. The scaffolding process for the Asian Clam genome showed a high level of efficiency (more than $99 \%$ genomic sequences and more than $97 \%$ contigs were located on chromosomes). The 18 chromosomes of $C$. fluminea covered $92.68 \%$ of the whole genome, and the longest chromosome $01(144.27 \mathrm{Mb})$ happened to be the largest scaffold we had ever assembled. These data results are strong evidence of our ultra-high quality genome.

R. philippinarum is an important economical bivalve with remarkable benthic adaptation and shell color diversity [80], and it has a lot in common with $C$. fluminea. The comparative result of $C$. fluminea and $R$. philippinarum genomes showed the assembly of $C$. fluminea were relatively good and improved a little comparing with that of $R$. philippinarum. They shared 244 syntenic blocks between two genomes, suggesting the genetic information between the two species has a lot in common, and the phylogenetic tree offer evidence for this point. The phylogenetic tree showed $C$. fluminea and its closest relative, $R$. philippinarum, diverged at an early stage of $\sim 228.89$ million years; the ancestors of $C$. fluminea and $R$. philippinarum, diverged from the common ancestors of other six bivalves, $\sim 492.00$ million years ago. Some references showed that Heterodonta living in the freshwaters originated in the Paleozoic [81-82], and Veneroida diversified during the Mesozoic and Cenozoic eras [83]. R. philippinarum as a kind of brackish water bivalve specie and $C$. fluminea as a kind of freshwater bivalve specie, the genetic distance between them and other marine species is relatively far. From this, we infer that the ancestors of $C$. fluminea may have invaded and migrated to freshwater from the ocean since millions of years ago, and they have evolved to fill various freshwater habitat.

On account of short sexual maturity time, rapid growth, short life cycle and planktonic veliger stage, $C$. fluminea has strong diffusion ability [84], and it is considered as an alien species in America and Europe [11-13]. The strong reproductive capacity and a powerful immune system might be bound to play an important role. In this study, we identified two gene families, MITF and NLRP, which were respectively related to the immune and reproductive adaptability of $C$. fluminea. It has been reported that 
microphthalmia-associated transcription factor (MITF) plays an important role in immune defense and shell color formation in molluscs [85-86]. We identified two MITF genes (EVM0008002 and EVM0031201) in the Asian Clam genome. They both encoded 533 amino acids, only three of which were different. These two genes were located on chromosome 10, and their physical distance was very close. Specifically, EVM0031201 was located at 46.99Mb-47.02Mb, and EVM0008002 was located at 47.05Mb47.08Mb. The EVM0031201 and EVM0008002 were so close to each other, which may be a duplication of the genome region, and this duplication may include one or more genes. Except for functions in apoptosis and inflammation, several NLRPs have been indicated as being involved in reproduction as well [87]. The 99 members of NLRP family in C. fluminea genome were significantly more than that of most of the candidate species, and the NLRP gene family was significantly expanded comparing to its ancestors, with 10 NLRP members. We infer the expansion of NLRP family may be related to the strong reproductive function of $C$. fluminea. The genomic information presented in our analysis will help to better understand, develop, and improve $C$. fluminea as well as establish a strong foundation for genomeassisted breeding programs in the future.

\section{Declarations}

\section{Conflict of interest}

The authors declare no conflict of interest exists.

\section{Author Contributions}

J.P., T.Z. and J.Y. designed and managed the project. T.Z. and J.Y. interpreted the data and drafted the manuscript. S.T., D.L. and X.G. prepared the materials. S.Z., W.S., X.L. and Y.L. preformed the DNA extraction, RNA extraction and libraries construction. J.Y., S.T. and D.L. performed the bioinformatics analysis. All authors contributed to the final manuscript editing.

\section{Data Accessibility}

Raw sequencing reads for PacBio and Illumina are available at GenBank as BioProject PRJNA657911. Raw sequencing data (Illumina, PacBio, and $\mathrm{Hi}-\mathrm{C}$ data) have been deposited in the SRA (Sequence Read Archive) database as SUB7507164. The data including assembly and annotation that supported the findings of this study have been deposited in the in the FigShare database,doi.org/10.6084/m9.figshare.12805886.v1 (https://doi.org/10.6084/m9.figshare.12805886.v1).

\section{Acknowledgements}


We appreciate the help from Jiangsu Marine Fisheries Research Institute during sample collection, the help from Lei Wu \& Shaofang He (Biomarker Technologies Corporation) in data analysis, and the suggestion from Xiaqing Yu (Nanjing Agricultural University) in writing. The bioinformatics analysis is achieved by Freshwater Fisheries Research Institute of Jiangsu Province. This work was supported by the major project of hydro bios resources in Jiangsu Province (ZYHB16-3), the monitoring of fishery resources in fishery waters of Jiangsu Province in 2018 (ZYHJ201801), the independent research project of Freshwater Fisheries Research Institute of Jiangsu Province - the identification of Corbicula species and genetic conservation unit in Jiangsu inland waters (BM2018027-SZL201901).

\section{References}

1. Ishibashi, R. et al. Androgenetic Reproduction in a Freshwater Diploid Clam Corbicula fluminea (Bivalvia: Corbiculidae). Zoolog. 20, 727-732 https://doi.org/10.2108/zsj.20.727 (2003).

2. Korniushin, A. V. A revision of some Asian and African freshwater clams assigned to Corbicula fluminalis (Müller, 1774) (Mollusca: Bivalvia: Corbiculidae), with a review of anatomical characters and reproductive features based on museum collections. Hydrobiologia. 529, 251-270 https://doi.org/10.1007/s10750-004-9322-x (2004).

3. Alyakrinskaya, I. O. Functional Significance and Weight Properties of the Shell in Some Mollusks. Biology Bulletin. 32, 397-418 https://doi.org/10.1007/s10525-005-0118-y (2005).

4. Qiu, A. D., Shi, A. J. \& Komaru, A. Yellow and brown shell color morphs of Corbicula fluminea (Bivalvia: Corbiculidae) from Sichuan province, china, are triploids and tetraploids. Journal of Shellfish Research. 20, 323-328 (2001).

5. James, H. \& Throp. \& Ecology and Classification of North American Freshwater Invertebrates. Quarterly Review of Biology. 39, 209 https://doi.org/10.1021/ba-1995-0246.pr001 (1991).

6. Tao, Z. Y., Deng, Y. H. \& Li, C. G. Embryonic and postembryonic development of Corbicula fluminea. Jiangsu Agricultural Sciences. 44, 305-307 (2016).

7. Gu, M. Q. \& Wang, Z. Embryonic development observation and staging of Corbicula fluminea (Müller). Fisheries information and strategy. 5, 28-29 (2001).

8. Ding, L. Y., Deng, Y. H. \& Cao, Y. H. Ecological environment indicator function of Corbicula fluminea. Contemporary fisheries. 8, 78-79 (2014).

9. Mcmahon, R. F. The Occurence and Spread of the Introduced Asiatic Freshwater Clam, Corbicula fluminea (Muller) in North America: 1924-1982. Nautilus. 96, 134-141 (1982).

10. Counts, C. L. Corbicula fluminea (Bivalvia: Sphacriacea) in British Columbia. Nautilus. 95, 12-13 (1981).

11. Beghelli, F. et al. First occurrence of the exotic Asian clam Corbicula fluminea (Muller, 1774) in the Jundiaí-Mirim River Basin, SP, Brazil. Ambiente \& Água - An Interdisciplinary. Journal of Applied Science. 9, 402 https://doi.org/10.4136/ambi-agua.1330 (2014). 
12. Schmidlin, S. \& Baur, B. Distribution and substrate preference of the invasive clam Corbicula fluminea in the river Rhine in the region of Basel (Switzerland, Germany, France). Aquatic Sciences 69, 153-161, doi:10.1007/s00027-006-0865-y (2007).

13. Cebulska, K. D. \& Krodkiewska, M. Further dispersion of the invasive alien species Corbicula fluminea (O. F. Müller, 1774) in the Oder River. Knowledge and Management of Aquatic Ecosystems. 420, 14 https://doi.org/10.1051/kmae/2019008 (2019).

14. Zhao, L. \& Liu, H. Q. Evaluation of protein nutritional value in Corbicula fluminea extraction. Anhui Agricultural Science. 23, 4105-4107 (2010).

15. Zhuang, P., Song, C. \& Zhang, L. Z. Analysis and evaluation of nutritional components of Corbicula fluminea in the Yangtze River Estuary. Acta nutrition Sinica. 31, 304-306 (2009).

16. Chin, L. H., Chien, C. H. \& Gow, C. Y. Hepatoprotection by freshwater clam extract against ccl4induced hepatic damage in rats. American Journal of Chinese Medicine. 38, 881-894 https://doi.org/10.1142/S0192415X10008329 (2010).

17. Peng, T. C. et al. Freshwater clam extract ameliorates acute liver injury induced by hemorrhage in rats. American Journal of Chinese Medicine. 36, 1121-1133 https://doi.org/10.1142/S0192415X08006466 (2008).

18. Wang, Y. \& Liu, D. H. Research status and Prospect of functional components of Corbicula fluminea. Food and fermentation industry. 36, 122-124 (2010).

19. Xiao, L. Z. et al. Effects of Corbicula fluminea in Lake Taihu on improvement of eutrophic water quality. Journal of Lake ences. 27, 486-492 (2015).

20. Sun, H. Utilization and culture of Corbicula fluminea. Scientific fish culture. 34, 30-31 (1995).

21. Lee, S. W. et al. A study of Edwardsiella tarda colonizing live Asian clam, Corbicula fluminea, from Pasir Mas, Kelantan, Malaysia with the emphasis on its antibiogram, heavy metal tolerance and genetic diversity. Veterinary Archives. 83, 130-135 (2013).

22. Gestal, C. et al. Study of Diseases and the Immune System of Bivalves Using Molecular Biology and Genomics. Reviews in Fisheries Science. 16, 133-156 https://doi.org/10.1080/10641260802325518 (2008).

23. Sun, J. et al. Adaptation to deep-sea chemosynthetic environments as revealed by mussel genomes. Nat Ecol Evol. 1, 121-126 https://doi.org/10.1038/s41559-017-0121 (2017).

24. Yan, X. et al. Color Diversity. IScience. 19, 1225-1237 https://doi.org/10.1016/j.isci.2019.08.049 (2019). Clam Genome Sequence Clarifies the Molecular Basis of Its Benthic Adaptation and Extraordinary Shell

25. André, G. et al. Molluscan genomics: the road so far and the way forward. Hydrobiologia. 6, 847-853 (2020).

26. Dunn, C. W. \& Ryan, J. F. The evolution of animal genomes. Current Opinion in Genetics \& Development. 35, 25-32 https://doi.org/10.1016/j.gde.2015.08.006 (2015). 
27. Altschul, S. F. et al. Basic local alignment search tool. Journal of molecular biology. 215, 403-410 https://doi.org/10.1016/S0022-2836(05)80360-2 (1990).

28. Chen, S. et al. fastp: an ultra-fast all-in-one FASTQ preprocessor. Bioinformatics. 34, 884-890 https://doi.org/10.1093/bioinformatics/bty560 (2018).

29. Marçais, G. \& Kingsford, C. A fast, lock-free approach for efficient parallel counting of occurrences of k-mers. Bioinformatics. 27, 764-770 https://doi.org/10.1093/bioinformatics/btr011 (2011).

30. Koren, S. et al. Canu: scalable and accurate long-read assembly via adaptive k-mer weighting and repeat separation. Genome Res. 27, 722-736 https://doi.org/10.1101/gr.215087.116 (2017).

31. Schmidt, M. H. et al. De Novo Assembly of a New Solanumpennellii Accession Using Nanopore Sequencing. Plant Cell. 29, 2336-2348 https://doi.org/10.1105/tpc.17.00521 (2017).

32. Vaser, R. et al. Fast and accurate de novo genome assembly from long uncorrected reads. Genome Res. 27, 737-746 https://doi.org/10.1101/gr.214270.11632 (2017).

33. Walker, B. J. et al. Pilon: an integrated tool for comprehensive microbial variant detection and genome assembly improvement. Plos One. 9, e112963 https://doi.org/10.1371/journal.pone.0112963 (2014).

34. Li, H. \& Durbin, R. Fast and accurate short read alignment with Burrows-Wheeler transform. Bioinformatics. 25, 1754-1760 https://doi.org/10.1093/bioinformatics/btp324 (2009).

35. Servant, N. et al. HiC-Pro: an optimized and flexible pipeline for Hi-C data processing. Genome Biol. 16, 259-262 https://doi.org/10.1186/s13059-015-0831-x (2015).

36. Burton, J. N. et al. Chromosome-scale scaffolding of de novo genome assemblies based on chromatin interactions. Nature Biotechnology. 31, 1119-1125 https://doi.org/10.1038/nbt.2727 (2013).

37. Xu, G. C. et al. LR_Gapcloser: a tiling path-based gap closer that uses long reads to complete genome assembly. Gigascience. 8, 157-160 https://doi.org/10.1093/gigascience/giy157 (2019).

38. Simao, F. A. et al. BUSCO: assessing genome assembly and annotation completeness with singlecopy orthologs. Bioinformatics. 31, 3210-3212 https://doi.org/10.1093/bioinformatics/btv351 (2015).

39. Parra, G., Bradnam, K. \& Korf, I. CEGMA: a pipeline to accurately annotate core genes in eukaryotic genomes. Bioinformatics. 23, 1061-1067 https://doi.org/10.1093/bioinformatics/btm071 (2007).

40. Xu, Z. \& Wang, H. LTR_FINDER: an efficient tool for the prediction of full-length LTR retrotransposons. Nucleic acids research. 35, 265-268 https://doi.org/10.1093/nar/gkm286 (2007).

41. Price, A. L., Jones, N. C. \& Pevzner, P. A. De novo identification of repeat families in large genomes. Bioinformatics. 21, 351-358 https://doi.org/10.1093/bioinformatics/bti1018 (2005).

42. Hoede, C. et al. PASTEC: an automatic transposable element classification tool. Plos One. 9, e91929 https://doi.org/10.1371/journal.pone.0091929 (2014).

43. Bao, W., Kojima, K. K. \& Kohany, O. Repbase Update, a database of repetitive elements in eukaryotic genomes. Mobile Dna. 6, 11 https://doi.org/10.1186/s13100-015-0041-9 (2015). 
44. Tarailo-Graovac, M. \& Chen, N. Using RepeatMasker to identify repetitive elements in genomic sequences. Current protocols in bioinformatics. 5, 11-14 https://doi.org/10.1002/0471250953.bi0410s25 (2009).

45. Burge, C. \& Karlin, S. Prediction of complete gene structures in human genomic DNA. Journal of molecular biology. 268, 78-94 https://doi.org/10.1006/jmbi.1997.0951 (1997).

46. Stanke, M. \& Waack, S. Gene prediction with a hidden Markov model and a new intron submodel. Bioinformatics. 19, 215-225 https://doi.org/10.1093/bioinformatics/btg1080 (2003).

47. Majoros, W. H., Pertea, M. \& Salzberg, S. L. TigrScan and GlimmerHMM: two open source ab initio eukaryotic gene-finders. Bioinformatics. 20, 2878-2879 https://doi.org/10.1093/bioinformatics/bth315 (2004).

48. Blanco, E., Parra, G. \& Guigó, R. Using geneid to identify genes. Current protocols in bioinformatics 18, 4.3.1-4.3.28, doi:10.1002/0471250953.bi0403s00 (2007).

49. Korf, I. Gene finding in novel genomes. BMC bioinformatics. 5, 59 https://doi.org/10.1186/14712105-5-59 (2004).

50. Keilwagen, J. et al. Using intron position conservation for homology-based gene prediction. Nucleic acids research. 44, 89 https://doi.org/10.1093/nar/gkw092 (2016).

51. Kim, D., Langmead, B. \& Salzberg, S. L. HISAT: a fast spliced aligner with low memory requirements. Nature Methods. 12, 357-360 https://doi.org/10.1038/nmeth.3317 (2015).

52. Pertea, M. et al. StringTie enables improved reconstruction of a transcriptome from RNA-seq reads. Nature Biotechnology. 33, 290-295 https://doi.org/10.1038/nbt.3122 (2015).

53. Tang, S., Lomsadze, A. \& Borodovsky, M. Identification of protein coding regions in RNA transcripts. Nucleic acids research. 43, 78 https://doi.org/10.1093/nar/gkv227 (2015).

54. Haas, B. J. et al. Automated eukaryotic gene structure annotation using EVidenceModeler and the Program to Assemble Spliced Alignments. Genome Biol. 9, 7 https://doi.org/10.1186/gb-2008-9-1-r7 (2008).

55. Haas, B. J. et al. Improving the Arabidopsis genome annotation using maximal transcript alignment assemblies. Nucleic acids research. 31, 5654-5666 https://doi.org/10.1093/nar/gkg770 (2003).

56. Griffiths-Jones, S. et al. miRBase: microRNA sequences, targets and gene nomenclature. Nucleic acids research. 34, 140-144 https://doi.org/10.1093/nar/gkj112 (2006).

57. Daub, J. et al. Rfam: Annotating Families of Non-Coding RNA Sequences. Methods in Molecular Biology, 349-363, New York, NY: Humana Press(2015).

58. She, R. et al. genBlastG: using BLAST searches to build homologous gene models. Bioinformatics. 27, 2141-2143 https://doi.org/10.1093/bioinformatics/btr342 (2011).

59. Lowe, T. M. \& Eddy, S. R. tRNAscan-SE: a program for improved detection of transfer RNA genes in genomic sequence. Nucleic acids research. 25, 955-964 https://doi.org/10.1093/nar/25.5.955 (1997). 
60. Nawrocki, E. P. \& Eddy, S. R. Infernal 1.1: 100-fold faster RNA homology searches. Bioinformatics. 29, 2933-2935 https://doi.org/10.1093/bioinformatics/btt509 (2013).

61. Tatusov, R. L. et al. The COG database: an updated version includes eukaryotes. BMC bioinformatics. 4, https://doi.org/10.1186/1471-2105-4-41 (2003).

62. Kanehisa, M. \& Goto, S. K. E. G. G. Kyoto Encyclopedia of Genes and Genomes. Nucleic acids research. 28, 27-30 https://doi.org/10.1093/nar/28.1.27 (2000).

63. Boeckmann, B. et al. The SWISS-PROT protein knowledgebase and its supplement TrEMBL in 2003. Nucleic acids research. 31, 365-370 https://doi.org/10.1093/nar/gkg095 (2003).

64. Marchler, B. et al. CDD: a Conserved Domain Database for the functional annotation of proteins. Nucleic Acids Res. 39, 225-229 https://doi.org/10.1093/nar/gkq1189 (2011).

65. Consortium, G. O. The Gene Ontology (GO) database and informatics resource. Nucleic acids research. 32, 258-261 https://doi.org/10.1093/nar/gkh036 (2004).

66. Conesa, A. et al. Blast2GO: a universal tool for annotation, visualization and analysis in functional genomics research. Bioinformatics. 21, 3674-3676 https://doi.org/10.1093/bioinformatics/bti610 (2005).

67. El-Gebali, S. et al. The Pfam protein families database in 2019. Nucleic Acids Res. 47, 427-432 https://doi.org/10.1093/nar/gky995 (2018).

68. Fu, L. et al. CD-HIT: accelerated for clustering the next-generation sequencing data. Bioinformatics. 28, 3150-3152 https://doi.org/10.1093/bioinformatics/bts565 (2012).

69. Li, L., Stoeckert, C. J. \& Roos, D. S. OrthoMCL: identification of ortholog groups for eukaryotic genomes. Genome Res. 13, 2178-2189 https://doi.org/10.1101/gr.1224503 (2003).

70. Edgar, R. C. MUSCLE: multiple sequence alignment with high accuracy and high throughput. Nucleic acids research. 32, 1792-1797 https://doi.org/10.1093/nar/gkh340 (2004).

71. Guindon, S. et al. New algorithms and methods to estimate maximum-likelihood phylogenies: assessing the performance of PhyML 3.0. Systematic biology. 59, 307-321 https://doi.org/10.1093/sysbio/syq010 (2010).

72. Yang, Z. PAML 4: Phylogenetic Analysis by Maximum Likelihood. Molecular Biology \& Evolution. 24, 1586-1591 https://doi.org/10.1093/molbev/msm088 (2007).

73. Kumar, S. et al. TimeTree: a resource for timelines, timetrees, and divergence times. Molecular Biology \& Evolution. 34, 1812-1819 https://doi.org/10.1093/molbev/msx116 (2017).

74. De, B. T. et al. CAFE: a computational tool for the study of gene family evolution. Bioinformatics. 22, 1269-1271 https://doi.org/10.1093/bioinformatics/btl097 (2006).

75. Zhao, G. Q. et al. Abasic helix-loop-helix protein, forms heterodimers with TFE3 and inhibits TFE3dependent transcription activation. Mol Cell Biol. 13, 4505-4512 https://doi.org/10.1128/MCB.13.8.4505 (1993).

76. Ting, J. P. et al. The NLR gene family: a standard nomenclature. Immunity. 28, 285-287 https://doi.org/10.1016/j.immuni.2008.02.005 (2008). 
77. Plazzi, F. \& Passamonti, M. Towards a molecular phylogeny of Mollusks: bivalves' early evolution as revealed by mitochondrial genes. Mol Phylogenet Evol. 57, 641-657 (2010).

78. Peterson, K. J. et al. The Ediacaran emergence of bilaterians: congruence between the genetic and the geological fossil records. Philos Trans R Soc Lond B Biol Sci. 363, 1435-1443 https://doi.org/10.1098/rstb.2007.2233 (1496).

79. Rüdiger, B. et al. Investigating the Bivalve Tree of Life-an exemplar-based approach combining molecular and novel morphological characters. Invertebrate Systematics. 28, 32-115 https://doi.org/10.1071/IS13010 (2014).

80. Zhang, G. F. et al. The oyster genome reveals stress adaptation and complexity of shell formation. Nature. 490, 49-54 https://doi.org/10.1038/nature11413 (2012).

81. Raymond, C. \& Moore. \& Treatise on invertebrate paleontology. Geological Society of America. 18, 167-172 (1969).

82. Cope, J. \& Veliger, C. The early evolution of the Bivalvia. Origin and, evolutionary. radiation of the Mollusca. 123, 342-335 (1995).

83. Stanley, S. M. Post-Paleozoic adaptive radiation of infaunal bivalve molluscs - a consequence of mantle fusion and siphon formation. J. Paleontol. 3, 214-229 (1968).

84. Mcmahon, R. F. Evolutionary and physiological adaptations of aquatic invasive animals: $r$ selection versus resistance. Canadian Journal of Fisheries \& Aquatic Sciences. 59, 1235-1244 https://doi.org/10.1139/f02-105 (2002).

85. Zhang, S. et al. Identification of a gene encoding microphthalmia-associated transcription factor and its association with shell color in the clam Meretrix petechialis. Comp Biochem Physiol. 34, 75-83 https://doi.org/10.1016/j.cbpb.2018.04.007 (2018).

86. Zhang, S. et al. Identification of an MITF gene and its polymorphisms associated with the Vibrio resistance trait in the clam Meretrix petechialis. Fish Shellfish Immunol. 13, 466-473 https://doi.org/10.1016/j.fsi.2017.07.035 (2017).

87. Zhang, P. et al. Expression analysis of the NLRP gene family suggests a role in human preimplantation development. PLoS One. 3, 2755 https://doi.org/10.1371/journal.pone.0002755 (2008).

\section{Figures}




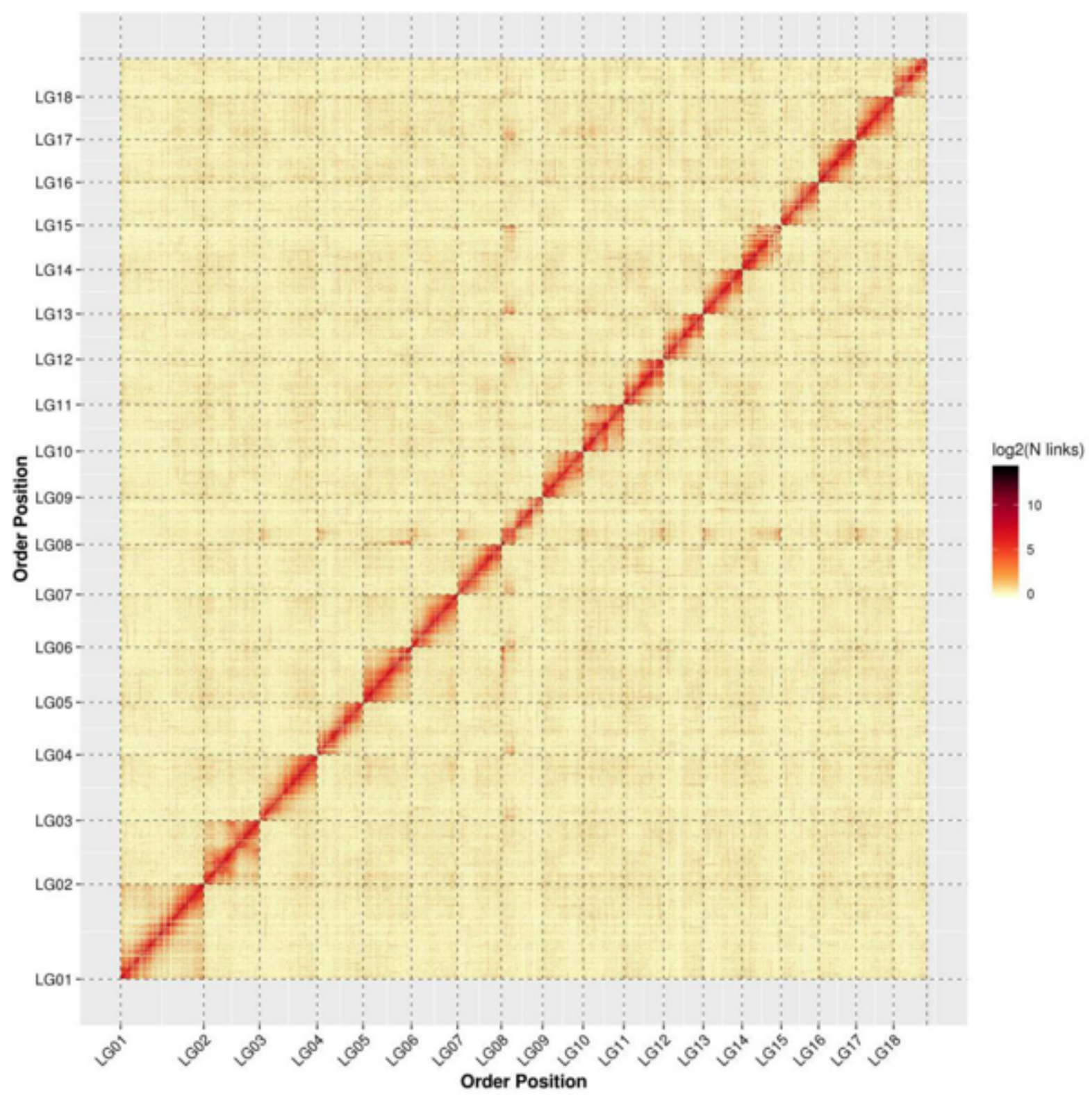

Figure 1

The genome-wide Hi-C heatmap of Corbicula fluminea. LG1-18 are the abbreviations of Lachesis Groups 1-18 representing the 18 pseudochromosomes. 

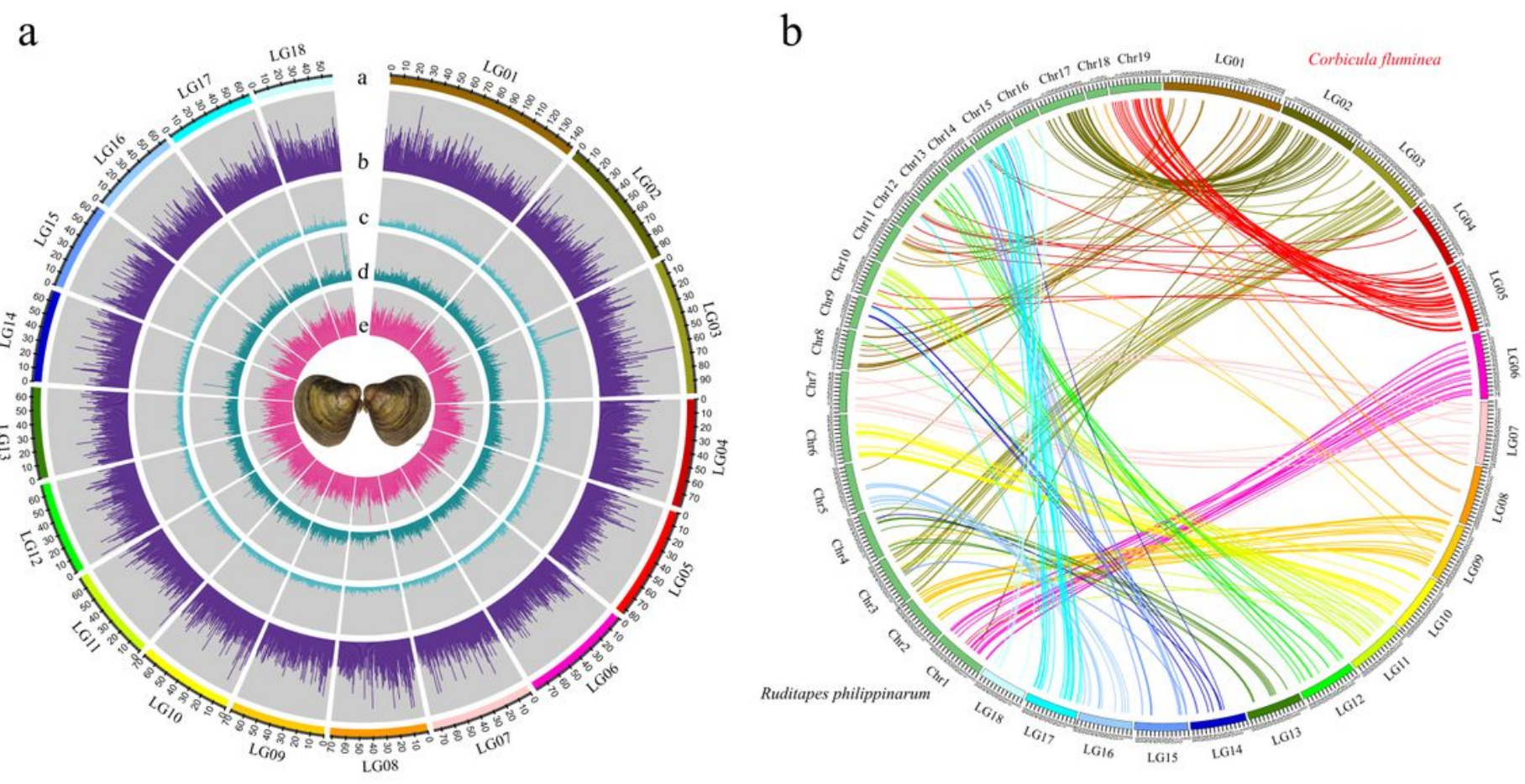

Figure 2

Genome landscape of Corbicula fluminea and the syntenic blocks between C. fluminea and Ruditapes philippinarum. (a) In the middle of the circle are C. fluminea. From outer to inner circles: a: marker distribution on 18 chromosomes at the Mb scale; b: LARD distribution on each chromosome; c: PLE distribution on each chromosome; d: gene distribution on each chromosome; e: GC content within a 1-Mb sliding window. (b) Syntenic blocks of C. fluminea and R. philippinarum. 
a

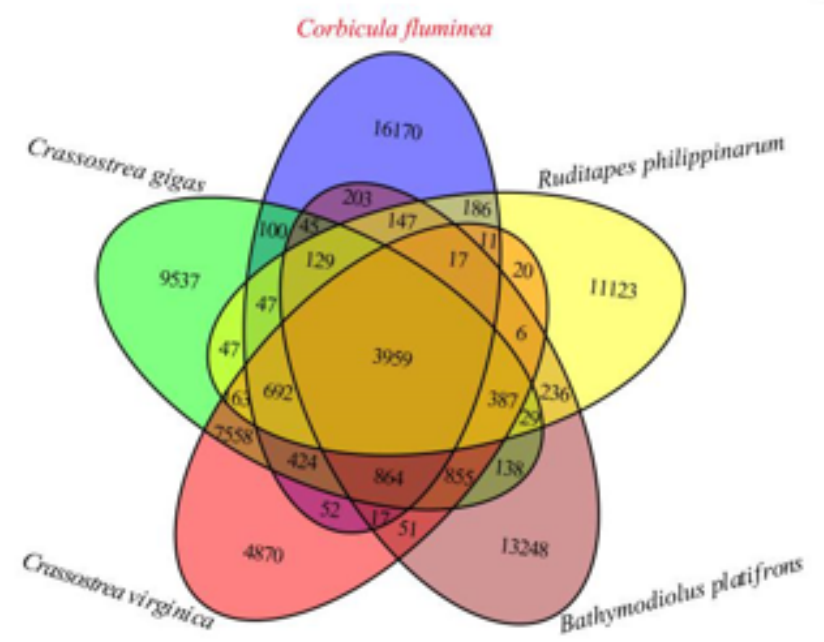

b

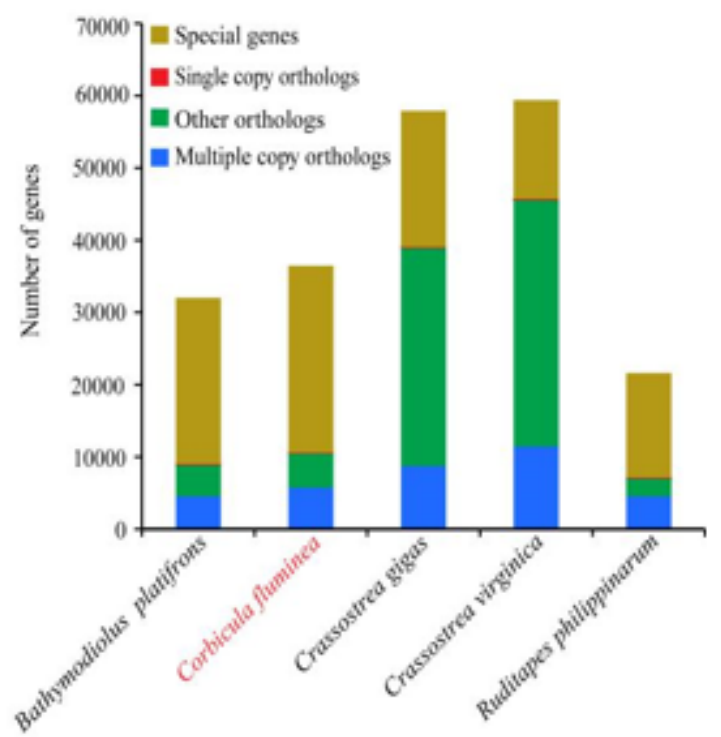

c

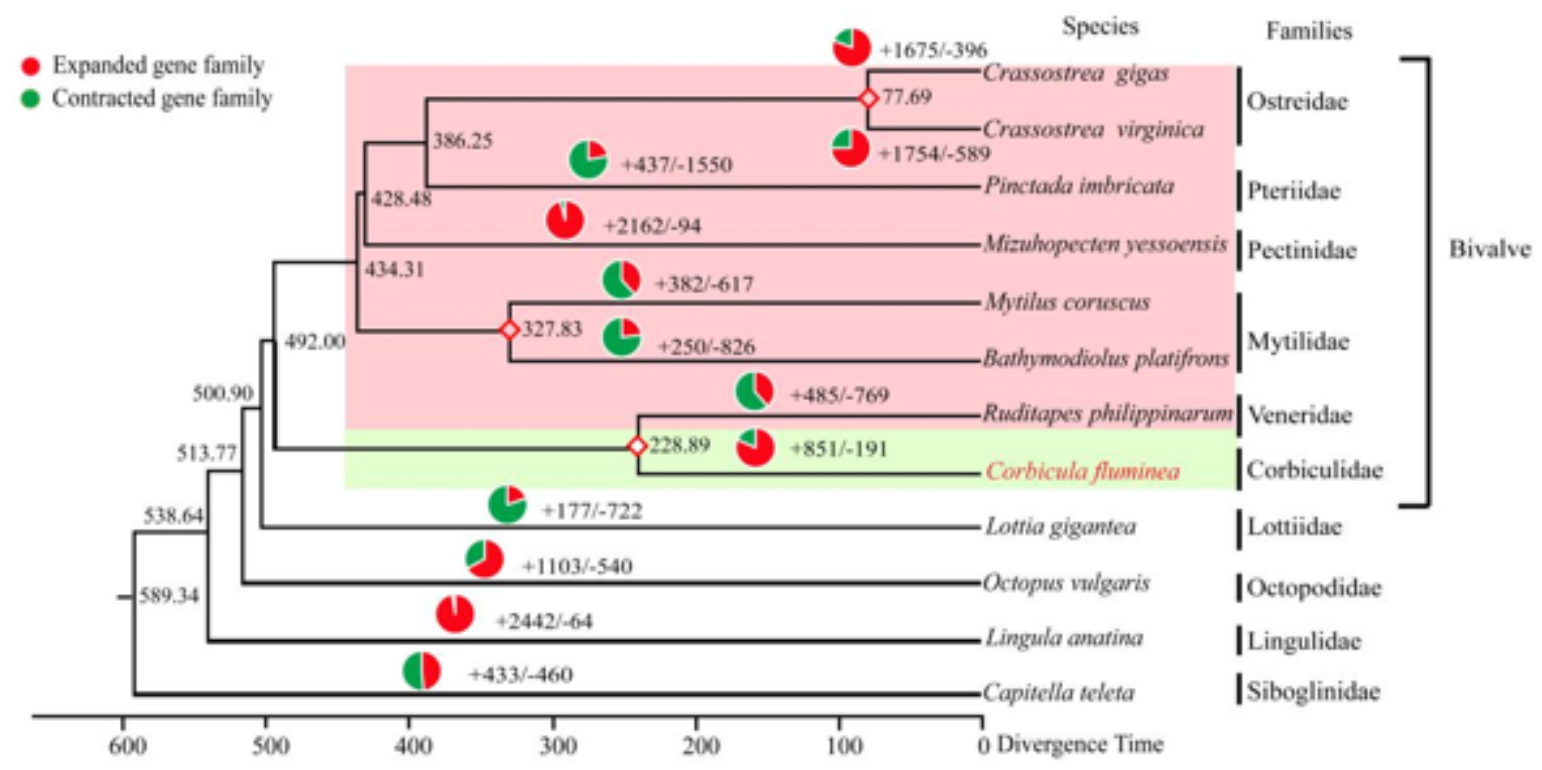

\section{Figure 3}

The comparative genomic analysis of Corbicula fluminea and other species. (a) Venn diagram of gene families between C. fluminea and Crassostrea gigas, Ruditapes philippinarum, Bathymodiolus platifrons, and Crassostrea virginica. (b) Distribution of multiple-copy orthologs, other orthologs, single-copy orthologs, and unique genes in C. fluminea and the above four species. (c) Phylogenetic tree, divergence time, and profiles of gene families that underwent expansion and contraction in 12 species. 
a

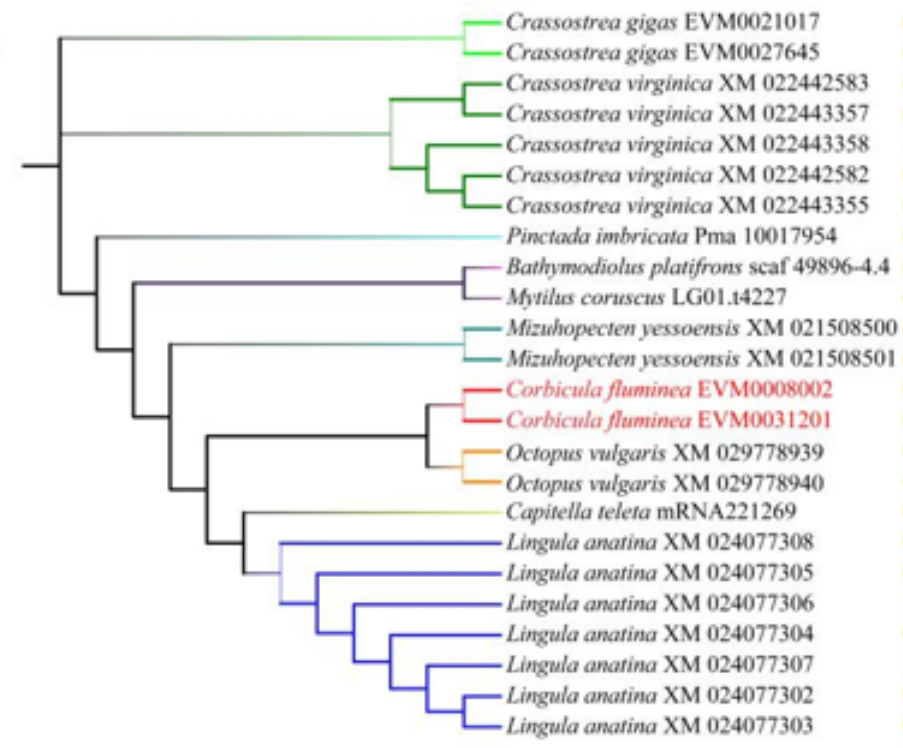

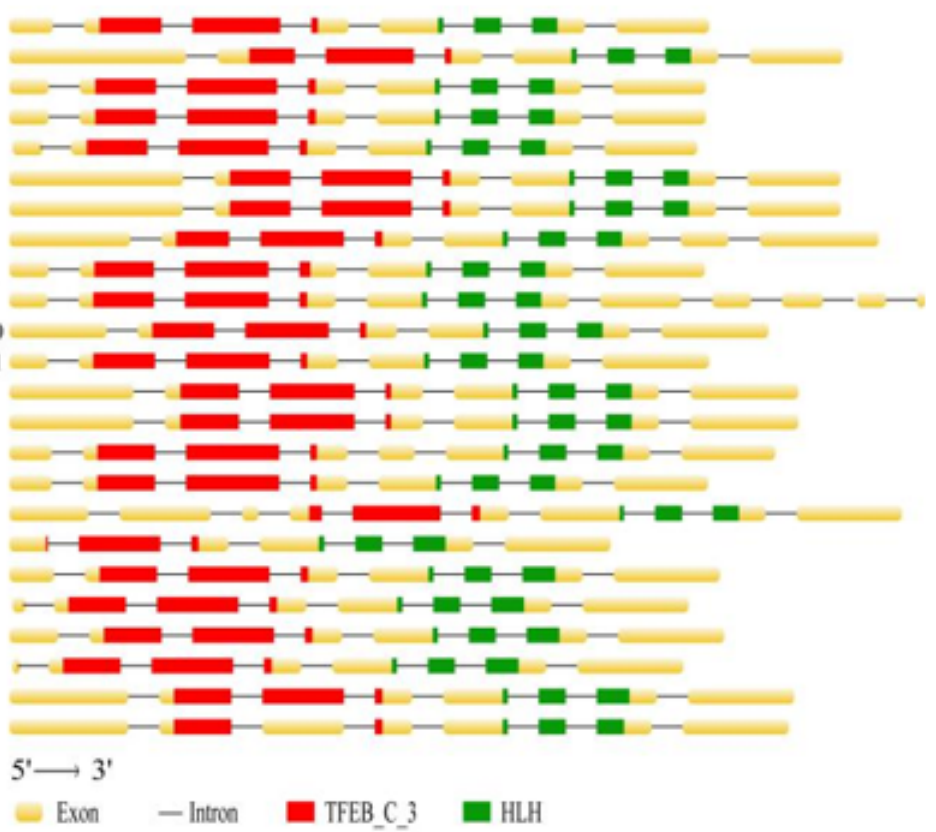

b

EVM0031201

EVM0008002

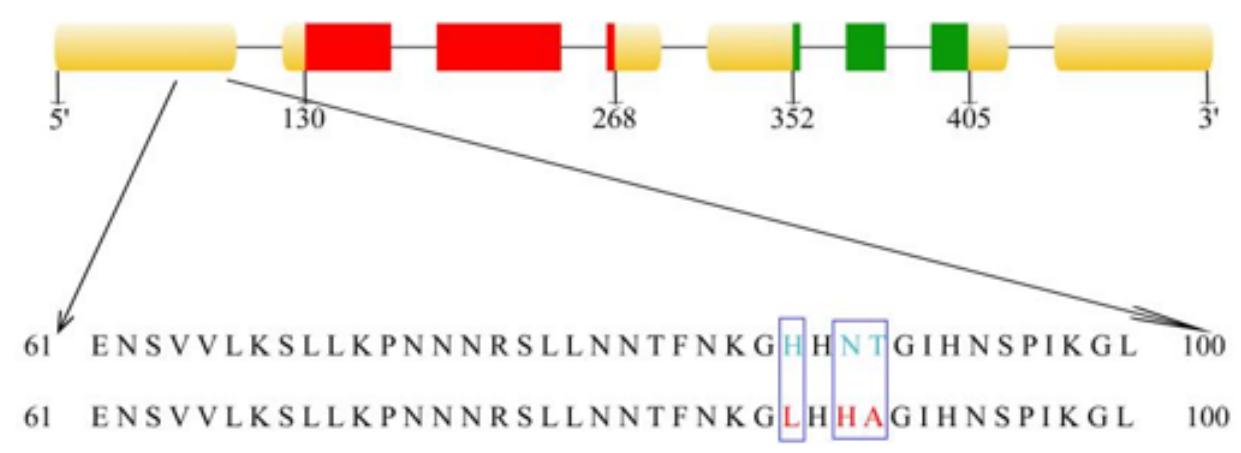

\section{Figure 4}

The analysis of MITF gene family. (a) The members of MITF family in Corbicula fluminea and other species. (b) The Commonalities and differences for MITF members in C. fluminea 
a

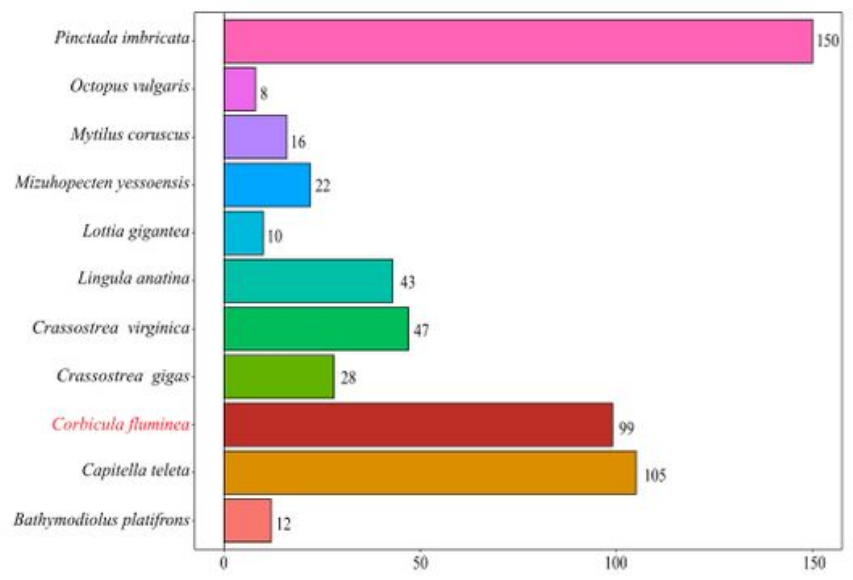

c

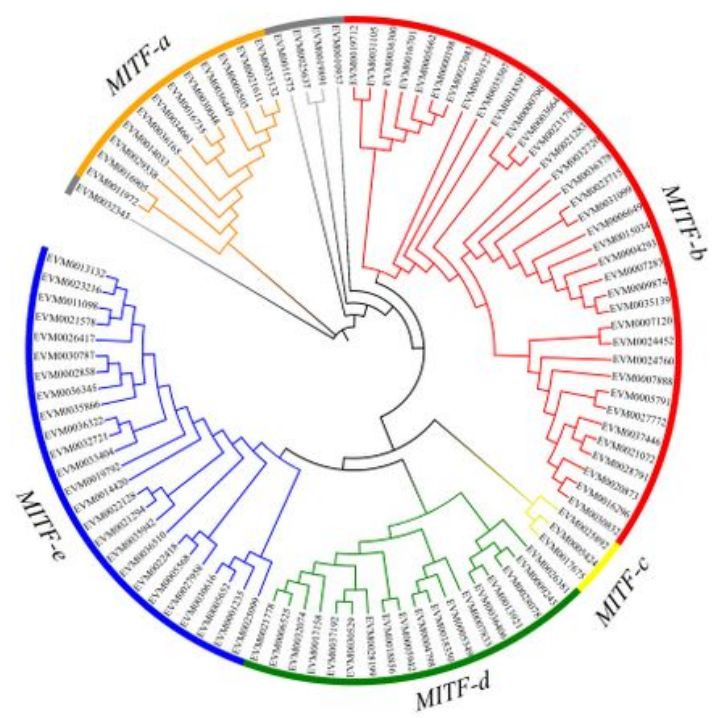

b

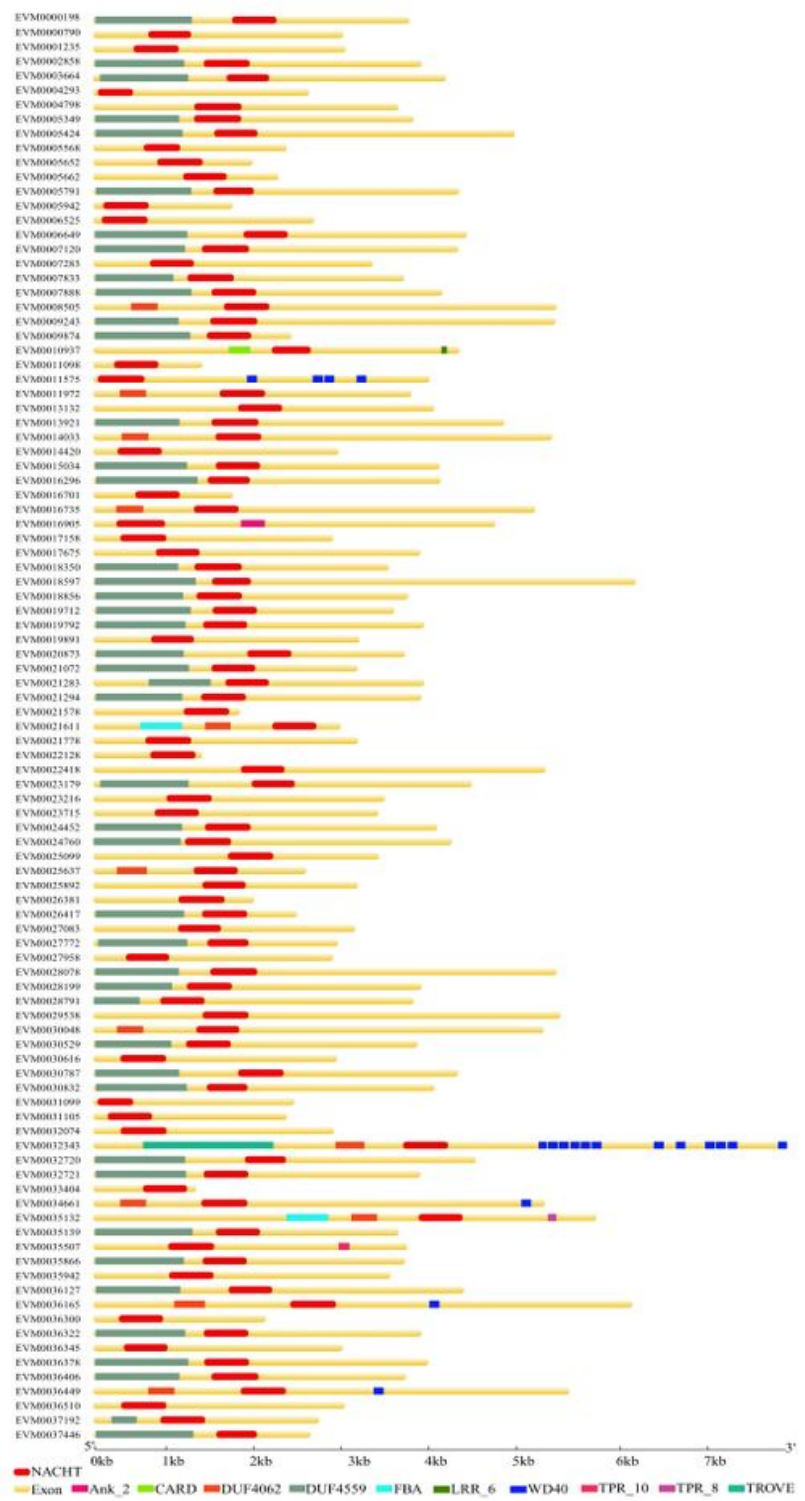

\section{Figure 5}

The analysis of NLRP gene family. (a) The number of NLRP members in Corbicula fluminea and other species. (b) The domains of NLRP members in C. fluminea. (c) NLRP members in C. fluminea were divided into five subfamilies, namely Subfamily a-e.

\section{Supplementary Files}

This is a list of supplementary files associated with this preprint. Click to download.

- FigureS1.png

- SupportingInformationTableS1S7S12.docx

- TableS9.xlsx 
- TableS10.xlsx

- Tables11.xlsx

- Tables13.xls

- Tables14.xls

- TableS15.xlsx

- Tables16.xls

- Tables17.xls

- Tables18.xlsx

- Tables19.xls

- Tables20.xIs 